\title{
Brief Report of Guidelines and Protocols for the Management of COVID-19
}

\author{
Fabricia Oliveira Oliveira' ${ }^{1}$, Larissa Moraes dos Santos Fonseca ${ }^{1}$, \\ Roberto Badaró ${ }^{1}$, Bruna Aparecida Souza Machado ${ }^{1 *}$ \\ ${ }^{1}$ SENAI Institute of Innovation (ISI) in Advanced Health Systems (CIMATEC ISI SAS), University \\ Center SENAI/CIMATEC, National Service of Industrial Learning - SENAI; Salvador, Bahia, Brazil
}

\begin{abstract}
In less than a year, the novel coronavirus rapidly changed the world scenario. To dealing with the fast spread of the disease, health associations coordinate data flows and issue guidelines to better mitigate the impact of the threat. Also, scientific groups around the world are working to ensure that all information about the mechanisms of the virus, transmission, and disease clinics is updated as the disease progresses. The objective of this study was to present the guidelines and recommendations for preventing, management strategies, clarifications about pandemics disinformation, and diagnosing COVID-19 infection in human specimens adopted from the main health centers and institutions in the world, such as WHO and Centers for Disease Control and Prevention (CDC). It is important to highlight that the rapid and effective enforcement of existing international and national action plans, as well as parallel review and improvisation, is facilitating the affected countries to contain transmission and possibly delay the peak of outbreak and mortality.
\end{abstract}

Keywords: Guidelines. Recommendations. WHO. CDC.

\section{Introduction}

In December 2019, a mass of pneumonia cases, caused by a newly identified $\beta$-coronavirus, occurred in Wuhan, China [1]. The World Health Organization (WHO), on 12 January 2020, initially named this coronavirus as the 2019-novel coronavirus (2019-nCoV) and, on February 11, 2020, officially named the disease as coronavirus disease 2019 (COVID-19) [2]. On the same day, The International Committee on Taxonomy of Viruses has proposed to name the causative agent of COVID-19 as severe acute respiratory syndrome Coronavirus 2 (SARS-CoV-2) [2].

COVID-19 has rapidly spread to other regions of China and around the world [2]. In Brazil, more than 4 million patients have been confirmed since the first case has been identified, on February 26, 2020 [3]. WHO declared COVID-19 as a pandemic in March 2020, and the disease now poses massive health, economic, and social burden globally $[4,5]$. This pandemic is further complicated by the

Received on 2 March 2020; revised 9 June 2020.

Address for correspondence: ISI-SENAI CIMATEC. Av. Orlando Gomes, 1845, Piatã. Zip Code: 41650-010. Salvador, Bahia, Brazil. E-mail: brunam@fieb.org.br.

J Bioeng. Tech. Appl. Health (D2020 by SENAI CIMATEC. substantial risk of viral spread and transmission by asymptomatic carriers [6].

To dealing with the rapid spread of the disease, health associations coordinate data flows and issue guidelines to better mitigate the impact of the threat. Also, scientific groups around the world are working to ensure that all information about the mechanisms of the virus, transmission, and disease clinics is updated as the disease progresses. Thus, new diagnostic and therapeutic therapies can be and are being developed quickly. Despite everything, many doubts still hover about the virus-host relationship and mainly about the evolution of the pandemic [7]. The constant updating of information reports, such as protocols and guidelines, is part of the pandemic coping mechanism. Operational planning has the function of balancing the situation and responding directly to the demands of COVID-19, assisting with health services to mitigating the collapse of the health system [8].

Overburdened health systems allow for a dramatic increase in both direct mortalities from an outbreak and indirect mortality from preventableand treatable vaccine diseases. Based on this scenario, countries make decisions that are necessary to balance the demands of responding directly to COVID-19, at the same time that strategic planning for coordinated actions to maintain the provision of essential health services is carried out [9]. For this 
reason, preparing and making documents available is essential to guide and provide immediate support to countries in responding to COVID-19. [10]. Nevertheless, they should not only be directed to national governments, but also the entire population. All relevant communication must be given to the public: what is known and unknown about the disease, what is being done, and the actions that must be taken regularly. Also, community participation in following the proposed guidelines contributes to a better-controlled situation [11].

Concerning diagnosis, the guidelines and protocols also serve to safely establish the diagnosis, as well as portraying the production of vaccines and alternative treatments in force. The nucleic acid amplification tests remain the mainstay diagnostics for laboratory confirmation of SARSCoV-2 infection, while serological antibody tests are used to aid contact tracing, epidemiological, and vaccine evaluation studies [12]. Currently, about 200 vaccines are in the process of development, some of them already in clinical trial stages. Most candidates are based mainly on viral protein, due to its essential role in viral infectivity $[12,13]$. Before the efficacy of such vaccines in humans, strong international coordination and collaboration between studies by pharmaceutical companies with regulatory agencies are necessary to limit further damage by SARS-CoV-2. With several COVID-19 vaccines approaching phase III trials, the Food and Drug Administration (US FDA) has launched a development and licensing guidelines for these products. The guidelines discuss possible outcomes of the immune responses that can be observed, as well as stipulate parameters such as the number of study participants, including monitoring them "ideally at least one to two years"; and on pre-licensing safety for preventive vaccines. Following these and other guidelines are important for development programs to focus on traditional approval through direct evidence of the vaccine's safety and efficacy in protecting humans from SARS-CoV-2 infection [14].

So, any follow-up of news related to COVID-19 must be documented and made available in an accessible manner, mainly to guide other countries in the reference recommendations on the pandemic. Therefore, the objective of this work was to present the guidelines and recommendations for preventing, management strategies, clarifications about pandemics disinformation and diagnosing COVID-19 infection in human specimens adopted from the main health centers and institutions in the world, such as WHO and Centers for Disease Control and Prevention (CDC). Since COVID-19 is a new infection and new scientific evidence based on expert reviews is still emerging, the contents reported in this work, such as new diagnostic methods or general tests, selection of biosafety specifications and recommendations, may undergo further updates.

\section{Method}

The method of this review was based on guidelines and protocols of the main associations and regulatory agencies, with a focus on actions to combat COVID-19. Figure 1 demonstrates in a simplified way the methods applied for the development of this review. It is worth mentioning that for the development of this study, the most recent documents, and articles were used on prevention information, pandemic preparedness, and information on possible and potential vaccines, in addition to other information considered relevant.

\section{Coronavirus Disease 2019}

The CoVs have become the major pathogens of emerging respiratory disease outbreaks. As of September 9, there were 27,973,127 confirmed cases worldwide, with 905,426 deaths. On average, every 24 hours, 234,498 new cases appear from people infected with SARS-CoV-2. In Brazil, the disease still grows considerably. With more than 4 million confirmed cases, Brazil ranks third among the countries with the highest number of cases, behind only the USA with $6,304,181$ cases and India with 4,562,414 cases [15]. It is worth mentioning that these numbers 
Figure 1. The method applied for the development of this study.

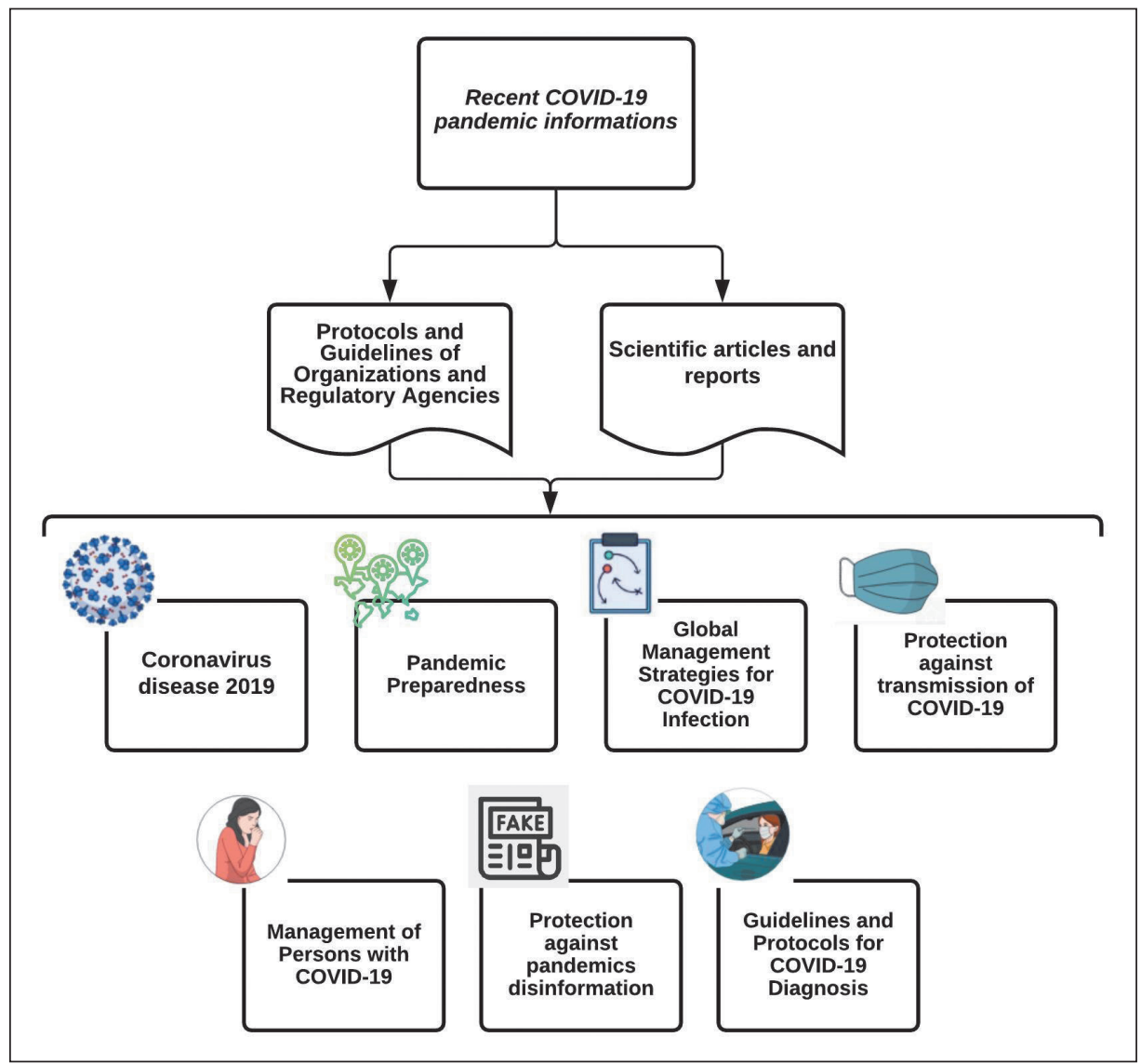

are possibly an underestimate of the infected and dead due to limitations of surveillance and testing. $\mathrm{CoV}$ virus family are a large family of singlestranded RNA viruses (+ssRNA). SARS-CoV-2 is a virus ranging from $60 \mathrm{~nm}$ to $140 \mathrm{~nm}$ in diameter with spike-like projections on its surface giving it a crownlike appearance under the electron microscope, hence the name coronavirus [16], that can be isolated in different animal species. For reasons yet to be explained, these viruses can cross species barriers and can cause, in humans, illness ranging from the common cold to more severe diseases such as MERS and SARS. Interestingly, these latter viruses have probably originated from bats and then moving into other mammalian hosts (the Himalayan palm civet for SARS-CoV, and the dromedary camel for MERS$\mathrm{CoV}$ ) before jumping to humans. The dynamics of SARS-CoV-2 are currently unknown, but there is speculation that it also has an animal origin [17] that, due to evidenced genetic relations, points to the bat as the primary host [18]. Regarding symptomatology, clinical features of COVID-19 include fever, dry cough, shortness of breath, normal or low levels of peripheral white blood cells, and inflammatory changes on chest X-ray [19].

All people, regardless of age group, are susceptible to SARS-CoV-2 infection. The infection occurs through large droplets generated during the cough and sneeze of symptomatic people, however, asymptomatic people are also liable to transmit the virus [20]. Studies have shown higher viral loads in the nasal cavity compared to the throat, with no difference in viral load between symptomatic and asymptomatic people. [21]. Patients can be infectious for the duration of symptoms and even during clinical recovery. Infection is acquired either by inhalation of these droplets or touching surfaces contaminated by them and then touching the nose, mouth, and eyes. The virus is also present in the stool and 
contamination of the water supply and subsequent transmission via aerosolization/feco oral route is also hypothesized [22].

\section{Pandemic Preparedness}

WHO and other leading epidemiology organizations unanimously agree on the indispensable role of pandemic preparation and a plan at global and national levels to mitigate the public health emergency of COVID-19 or any future outbreaks [23,24]. Pandemic preparation is an effort of the government and the society requiring inputs from each person susceptible to the infection agent as well as policymakers at national and international levels, frontline healthcare providers, infrastructure developers, and maintenance personnel, pharmaceutical industry and researcher community, and so forth [25]. Moreover, the pandemic preparedness plan needs constant reviewing and improvisation.

The magnitude of the COVID-19 pandemic requires worldwide action plans. The United States quickly created the United Nations Strategic Preparedness and Response Plan (SPRS) to control the transmission of the virus to delaying the spread of COVID-19, provide optimal care for all patients, and minimize the impact on healthcare systems and socioeconomic activities [26]. Several nations are well placed to implement this action plan with minimal support. However, each country has its issues that the placing authority has to adjust the guidelines and protocols for the reality of each country or district. Thus, all nation has to prepare a COVID-19 Country Preparedness and Response Plan (CPRP) against the COVID-19 [27]. These CPRPs need constant monitoring and reviewing using indicators shared by WHO and CDC, for example, updating as the situation evolves. Part of these plans is the protocols and guidelines adopted in each country [28].

Saxena, 2020 [27] reported that the success against a pandemic is grounded in the following actions, which have to be included in the protocols and guidelines: (i) Surveillance of the pathogen: characterization, epidemiology, transmission, symptoms, pathogenesis, diagnosis and detection, infection, contact tracing, data from confirmed cases, predicting mass infection outbreak, keeping a count, and estimation of mortality.

(ii) Response management: production and supply of protective/preventive pharmaceutical interventions or nonpharmaceutical interventions; extensive test the community, education of the community about the disease and how it spreads, transmit and all information about the disease.

(iii) Facilitating timely medical help: access to hospitals/healthcare providers, personal and public hygiene, disinfection, and quarantine services.

(iv) Lessons learned from the present outbreak to facilitate future action plans and preparedness.

\section{Global Management Strategies for COVID-19 Infection}

The authorities of worldwide and Health Organizations created strategies, which including protocols and guidelines, due to the exponential transmission of SARS-CoV-2 and social-economic impact of the pandemic [24,29,30], such as social distancing, travel restrictions, implementation of personal and public hygiene (non-pharmaceutical interventions), implementation of diagnosis (clinical with symptoms and laboratory), extensive testing for community and medicines interventions. All these practices are necessary to delay the peaking of the outbreak, avoid burden on the healthcare infrastructure, and "flattening the curve" of the infected patients $[25,31]$.

\section{Protection against Transmission of COVID-19}

According to $\mathrm{WHO}$ [32], individual protections against the transmission of COVID-19 between 
people are: Regularly and thoroughly clean your hands with an alcohol-based hand rub or wash them with soap and water. This practice kills viruses that may be on your hands; Maintain at least 1 meter (3 feet) distance between yourself and others. Therefore, when someone coughs, sneezes, or speaks, spraying small liquid droplets from their nose or mouth which may contain the virus, you are not too close to breathe in the droplets, including the COVID-19 virus if the person has the disease; Avoid going to crowded places. Where people come together in crowds, you are more likely to come into close contact with someone that has COVID-19 and it is more difficult to maintain physical distance of 1 meter (3 feet); Avoid touching eyes, nose, and mouth. Hands touch many surfaces and can pick up viruses. Once contaminated, hands can transfer the virus to your eyes, nose, or mouth. From there, the virus can enter your body and infect you. Make sure you, and the people around you, follow good respiratory hygiene. This means covering your mouth and nose with your bent elbow or tissue when you cough or sneeze. Then dispose of the used tissue immediately and wash your hands. Droplets spread the virus. By following good respiratory hygiene, you protect the people around you from viruses such as cold, flu, and COVID-19; Stay home and self-isolate even with minor symptoms such as cough, headache, mild fever, until you recover. Have someone bring you supplies. If you need to leave your house, wear a mask to avoid infecting others. Avoiding contact with others will protect them from possible COVID-19 and other viruses; If you have a fever, cough, and difficulty breathing, seek medical attention, but call by telephone in advance if possible and follow the directions of your local health authority. National and local authorities will have the most up to date information on the situation in your area. Calling in advance will allow your health care provider to quickly direct you to the right health facility. This will also protect you and help prevent the spread of viruses and other infections.

Keep up to date on the latest information from trusted sources, such as WHO or your local and national health authorities. Local and national authorities are best placed to advise on what people in your area should be doing to protect themselves. The guidelines proposed by the CDC first preconize the knowledge about how the virus spreads [33]. The virus is thought to spread mainly from person-to-person, but can also be spread between people who are in close contact with one another, and through respiratory droplets produced when an infected person coughs, sneezes, or talks [33]. These droplets can land in the mouths or noses of people who are nearby or possibly be inhaled into the lungs. It is important to highlight that some recent studies have suggested that COVID-19 may be spread by people who are not showing symptoms [6,34]. Therefore, until an effective vaccine or antiviral drug be developed, the unique way to not spread the virus is by practicing social distancing.

Some other steps are also indicated, such as: Often wash hands with soap and water for at least 20 seconds especially in a public place, or after blowing your nose, coughing, or sneezing; Avoid close contact, especially with people who are sick; Cover your mouth and nose with a cloth face cover when around others; Cover coughs and sneezes; Clean and disinfect; Monitor health by being alert for symptoms: watch for fever, cough, shortness of breath, or other symptoms of COVID-19.

\section{Management of Persons with COVID-19}

Patients with severe acute respiratory syndrome coronavirus 2 (SARS-CoV-2) infection can experience a range of clinical manifestations, from no symptoms to critical illness. This section of the Guidelines discusses the clinical management of patients according to illness severity. Currently, the Food and Drug Administration has not approved any drugs for the treatment of COVID-19. However, an array of drugs approved for other indications, as well as multiple investigational agents, are being studied for the treatment of COVID-19 in several hundred clinical trials around the globe. Some drugs can be 
accessed through Emergency Use Authorization, expanded access programs, or compassionate use mechanisms. Available clinical data for these drugs under investigation are discussed in Antiviral Therapy and Immune-Based Therapy.

In general, adults with COVID-19 can be grouped into the following severity of illness categories, although the criteria in each category may overlap or vary across guidelines and clinical trials:

(i) Asymptomatic or Presymptomatic Infection: Individuals who test positive for SARS-CoV-2 by virologic testing using a molecular diagnostic (e.g., polymerase chain reaction) or antigen test, but have no symptoms.

(ii) Mild Illness: Individuals who have any of the various signs and symptoms of COVID-19 (e.g., fever, cough, sore throat, malaise, headache, muscle pain) without shortness of breath, dyspnea, or abnormal chest imaging.

(iii) Moderate Illness: Individuals who have evidence of lower respiratory disease by clinical assessment or imaging and saturation of oxygen $\left(\mathrm{SpO}_{2}\right) \geq 94 \%$ on room air at sea level. Severe Illness: Individuals who have respiratory frequency $>30$ breaths per minute, $\mathrm{SpO}_{2}<94 \%$ on room air at sea level, the ratio of the arterial partial pressure of oxygen to fraction of inspired oxygen $\left(\mathrm{PaO}_{2} / \mathrm{FiO}_{2}\right)<300 \mathrm{mmHg}$, or lung infiltrates $>50 \%$.

(iv) Critical Illness: Individuals who have respiratory failure, septic shock, and/or multiple organ dysfunction.

In pediatric patients, radiographic abnormalities are common and, for the most part, should not be used as the sole criteria to define the COVID-19 illness category. Normal values for respiratory rate also vary with age in children, thus hypoxia should be the primary criterion to define severe illness, especially in younger children.

\section{Protection against Pandemics Disinformation}

Since SARS-CoV-2 is a novel virus, there is a knowledge gap that has been proven to be a breeding ground for the spread of false and/ or misleading information. The Department of Evidence and Intelligence for Action in Health of the Pan American Health Organization (PAHO) has stated that the "infodemic" - an overabundance of information - make the pandemic worse since makes it hard for people to find trustworthy sources and reliable guidance when they need it, and anybody can write or publish anything on the web [35]. Moreover, it can affect decisionmaking processes and there is no quality control on what is published. According to PAHO [35], people can help in the fight against the COVID-19 infodemic by Identifying evidence; Avoid fake news; Support open science; Determine if the information adds up; Report harmful rumors; Confirm that the information has been shared before by other people; Participate responsibly in social conversations; and, Share information responsibly.

Aiming to fight misinformation, WHO has joined forces with the Government of the United Kingdom and is running an awareness campaign called "Stop The Spread" [36]. The campaign is about the risks of the spread of false and incorrect information about the coronavirus pandemic aiming to raise awareness about the risks of misinformation, encouraging people to doublecheck information with trusted sources and is also being promoted in many countries across Africa, Asia, Europe, Middle East, and Latin America.

With the same purpose, an important action adopted by the European Union is the Joint Communication "Tackling COVID-19 disinformation - Getting the facts right" focused on the response to disinformation around the coronavirus pandemic [37]. In this communication, it is highlighted that first of all, there is a need to differentiate the various forms of false or misleading information, distinguishing the illegal content from the content that is harmful 
but not illegal. The next step is to determine if exists an intention to deceive or cause public harm, or to make an economic gain, qualifying it as disinformation. If there is no such intention, the content can be qualified as misinformation. The EU guides to address misinformation through grounded rebuttals and myth-busting and media literacy initiatives, differently from disinformation, that needs to be addressed through actions taken by governments. The main actions of the plan are: Strengthening Strategic Communication Within and Outside The EU; Cooperating Better Within the EU; Cooperation with Third Countries and International Partners; Greater Transparency of Online Platforms About Disinformation and Influence Operations; Ensuring Freedom of Expression and Pluralistic Democratic Debate; Empowering and Raising Citizen Awareness; Protecting Public Health and Consumers' Rights.

In Brazil, the Ministry of Health has made available a WhatsApp phone number for the population as an exclusive channel to receive viral information that will be investigated by the technical areas and officially answered if they are true or false [38].

\section{Guidelines and Protocols for COVID-19 Diagnosis}

Early recognition and rapid diagnosis are essential in interrupting the transmission chain of SARS-CoV-2. To diagnose patients, the decision must be based on clinical and epidemiological factors, linked to an analysis of the probability of infection [39]. According to the Guidelines on Response to Coronavirus Disease 2019 published by Korea Centers for Disease Control and Prevention (CDC) [40], case definitions are applied under conditions of serious alert levels, as is the case with COVID-19. They are divided into three types of definitions:

(i) Confirmed case: a case with infection confirmed by the realization of the gold standard RT-qPCR test in real-time, regardless of the clinical manifestation. (ii) Suspected case: when the patient has a fever above $37.5^{\circ} \mathrm{C}$ and/or respiratory symptoms within 14 days after close contact with a confirmed case.

(iii) Patient under investigation (PUI): cases suspected of having COVID-19 based on the opinion of a doctor, or that fit the definition of a previous case or that have an epidemiological correlation with a massive domestic outbreak of COVID-19.

Currently, the COVID-19 investigation includes the techniques of molecular testing of SARSCoV-2 nucleic acid amplification by real-time PCR preceded by reverse transcription reaction (RT-qPCR); and immunological tests (rapid test or classic serology for antibody detection). The partial or total sequencing of the viral genome, although is not a diagnostic method, can be investigatively used in epidemiological studies, when necessary [41]. The laboratory diagnosis considered the gold standard, as previously mentioned, is RTqPCR, as recommended by the guidelines of the World Health Organization (WHO) and Centers for Disease Control and Prevention (CDC) [39]. This molecular test is based on the detection of unique viral RNA sequences, with confirmation by nucleic acid sequencing, when necessary. It is worth mentioning that several protocols for this test have been proposed for the diagnosis of COVID-19, worldwide [39,42-45]. The difference between the molecular test and the serological/ immunological tests is based on the application. While RT-qPCR is used for diagnosing patients with COVID-19, serological tests are not indicated for diagnostic confirmation, and are recommended for surveillance purposes only [41]. This happens due to the period of the immunological window in the initial period of infection, where the production of $\operatorname{IgM}$ and $\operatorname{IgG}$ antibodies normally only occurs after 7 days (IgM) and 14 days (IgG), which reduces the sensitivity of this type of test in the first infection days [46].

RT-qPCR is a special version used when the genetic material targeted for detection is RNA. 
It is a very fast, sensitive, and reliable test, capable of producing results in 3 to 4 hours. Viral RNA is converted to DNA, copied several times using repeated temperature cycles in a PCR machine, and its detection is made by applying fluorescent markers that, when exceeding a certain level of fluorescence, indicates that the virus was present in that sample collected [46]. Originally, the method used radioactive isotope markers, however, this type of genetic marker was replaced by special markers, mostly fluorescent dyes, thus allowing almost immediate visualization of the results while the process is still in progress (realtime). The first SARS-CoV-2 detection protocol using this technique was developed by China's $\mathrm{CDC}$ and is based on the detection of the $\mathrm{N}$ and ORF1ab genes [47]. In this test, the positive result for the presence of the virus is reported when both markers are amplified [48], and a different result from this means that the test needs to be repeated for real confirmation $[49,50]$. The same recommendation is made by the US CDC, which if only one target is positive in the $\mathrm{N}$ region target, the result is considered inconclusive and needs to be re-tested [48]. Outside China, the first RT-qPCR protocol was incorporated primers targeting genes of the $\mathrm{E}, \mathrm{N}$, and RdRp, developed by Charité Institute (Germany) [43]. Also, other protocols were developed by the HKU Institute, Hong Kong, which is based on the amplification of the ORF1b-nsp and $\mathrm{N}$ genes. The National Institute of Infectious Diseases, Department of Virology III, Japan, for the Japan Pancorona and multiple targets, and $\mathrm{S}$ genes. The National Institute of Health in Thailand, for marker $\mathrm{N}$ and the Pasteur Institute in France, which is based on the detection of two regions in RdRp. Table 1 shows a summary regarding the interpretation of the results based on the Centers for Disease Control and Prevention's diagnostic panel [45].

The diagnostic accuracy of the RT-qPCR for the identification of patients with COVID-19 can be influenced by the type of sample used in the test, in addition to the time of evolution of the condition [51,52]. In general, sputum, nasopharyngeal swab (NP), and oropharyngeal swabs (OP) are the most common sample types taken from patients with mild to moderate illness. If both NP and OP are collected, they can be placed in the same tube and tested simultaneously to save reagents [53]. In general, the bronchoalveolar lavage (BAL) showed the highest positive rates, followed by sputum, NP, and OP in order of decreasing sensitivity $[21,54,55]$. Throat

Table 1. Real-Time RT-qPCR diagnostic panel.

\begin{tabular}{|c|c|c|c|c|c|}
\hline N1 & $\mathbf{N} 2$ & $\mathbf{R P}$ & $\begin{array}{l}\text { Result } \\
\text { Interpretation }\end{array}$ & Report & Action \\
\hline+ & + & $+/-$ & $\begin{array}{l}\text { SARS-CoV-2 } \\
\text { detected }\end{array}$ & $\begin{array}{l}\text { SARS-CoV-2 } \\
\text { positive }\end{array}$ & $\begin{array}{l}\text { Issue a report and notify the } \\
\text { responsible health agency }\end{array}$ \\
\hline \multicolumn{2}{|c|}{$\begin{array}{l}\text { If only one of } \\
\text { the two targets } \\
\text { is positive }\end{array}$} & $+/-$ & Inconclusive & Inconclusive & $\begin{array}{l}\text { Repeat the RT-qPCR and/or } \\
\text { extraction. If the repeated result } \\
\text { remains inconclusive, contact } \\
\text { for a third test }\end{array}$ \\
\hline- & - & + & $\begin{array}{l}\text { SARS-CoV-2 } \\
\text { not detected }\end{array}$ & Not detected & $\begin{array}{l}\text { Notify responsible health } \\
\text { agency. Consider testing for } \\
\text { other respiratory viruses }\end{array}$ \\
\hline- & - & - & Invalid & Invalid & $\begin{array}{l}\text { Repeat the extraction and RT- } \\
\text { qPCR. If the repeated result } \\
\text { remains invalid, consider taking } \\
\text { a new sample from the patient }\end{array}$ \\
\hline
\end{tabular}


gargling samples are an alternative specimen, although they are less sensitive than sputum [55]. Considering the seasonality of respiratory viruses, this collection must be performed until the 7 th day after the appearance of the first signs or symptoms [41]. It should be noted that the techniques employed in carrying out the RT-qPCR tests can also influence the diagnostic accuracy of the test [56], for this reason, the follow-up of tests classified in the guidelines of the WHO or other regulatory agencies is of paramount importance for maintaining the accuracy of the test.

\section{Conclusion}

The COVID-19 pandemic is spreading fast and new information about the disease comes up every day. It is important to believe that even during this current challenge that the world is experiencing, one cannot abdicate the principles of evidencebased medicine, recommendations, and guidelines grounded on high-level evidence, taking into account the professional obligations and social role of the responsible organizations as health providers. The rapid and effective enforcement of existing international and national action plans, as well as parallel review and improvisation, is facilitating the affected countries to contain transmission and possibly delay the peak of outbreak and mortality. Although the global economy is suffering from the pandemic. Therefore, it is important to review the current action plans and suitably improvise future action plans to mitigate the disease and avoid potential recurrences.

\section{References}

1. Lauxmann MA, Santucci NE, Autrán-Gómez AM. The SARS-CoV-2 coronavirus and the COVID-19 outbreak. International Braz J Urol. Brazilian Society of Urology, 2020.

2. Helmy YA, Fawzy M, Elaswad A, Sobieh A, Kenney SP, Shehata AA. The COVID-19 Pandemic: A Comprehensive Review of Taxonomy, Genetics, Epidemiology, Diagnosis, Treatment, and Control. J Clin Med, 2020.

3. Ministério da Saúde. Coronavírus Brasil, 2020.

4. Liu YC, Kuo RL, Shih S-R. COVID-19: the First Documented Coronavirus Pandemic in History. Biomed J, 2020 .
5. Cheval S, Adamescu CM, Georgiadis T, Herrnegger M, Piticar A, Legates DR. Observed and potential impacts of the COVID-19 pandemic on the environment. Vol. 17, International Journal of Environmental Research and Public Health. MDPI AG; 2020.

6. Lee S, Meyler P, Mozel M, Tauh T, Merchant R. Asymptomatic carriage and transmission of SARS-CoV-2: What do we know? Vol. 67, Canadian Journal of Anesthesia. Springer; 2020.

7. Cascella M, Rajnik M, Cuomo A, Dulebohn SC, Napoli R Di. Features, Evaluation, and Treatment of Coronavirus (COVID-19). Treasure Island (FL): StatPearls Publishing; 2020. p. 1-22.

8. World Health Organization. WHO releases guidelines to help countries maintain essential health services during the COVID-19 pandemic. News release, 2020.

9. World Health Organization. Maintaining essential health services: operational guidance for the COVID-19 context, 2020.

10. World Health Organization. COVID-19 Strategic Preparedness and Reponse Plan: Operational planning guidelines to support country preparedness and response, 2020.

11. World Health Organization. Public Health Surveillance for COVID-19, 2020.

12. Shih H-I, Wu C-J, Tu Y-F, Chi C-Y. Fighting COVID-19: A quick review of diagnoses, therapies, and vaccines. Biomed J, 2020.

13. Callaway E, Ledford H, Mallapaty S. Six months of coronavirus: the mysteries scientists are still racing to solve. Nature, 2020

14. Mullard A. COVID-19 vaccine guidelines. Nat Rev, 2020.

15. World Health Organization (WHO). Weekly Operational Update on COVID-19, 2020.

16. Richman DD, Whitley RJ, Hayden FG. Clinical Virology, 4th ed. Washington: ASM Press; 2016. pp. 575-597.

17. Cascella M, Rajnik M, Cuomo A, Dulebohn SC, Napoli R Di. Features, Evaluation, and Treatment of Coronavirus (COVID-19). Treasure Island (FL): StatPearls Publishing; 2020. p. 1-22.

18. Li Q, Guan X, Wu P, Wang X, Zhou L, et al. Early transmission dynamics in Wuhan, China, of novel coronavirus-infected pneumonia. N Engl J Med, 2020.

19. Huang X, Wei F, Hu L, Wen L, Chen K. Epidemiology and clinical characteristics of COVID-19. Vol. 23, Archives of Iranian Medicine. Academy of Medical Sciences of I.R. Iran; 2020. p. 268-71.

20. Rothe C, Schunk M, Sothmann P, Bretzel G, Froeschl G, Wallrauch C, Zimmer T, Thiel V, Janke C, Guggemos W, Seilmaier M, Drosten C, Vollmar P, Zwirglmaier K, Zange S, Wölfel R, Hoelscher M. Transmission of 2019-nCoV Infection from an Asymptomatic Contact in Germany. N Engl J Med, 2020.

21. Zou L, Ruan F, Huang M, Liang L, Huang H, Hong Z, Yu J, Kang M, Song Y, Xia J, Guo Q, Song T, He J, Yen H-L, Peiris M, Wu J. SARS-CoV-2 Viral Load in Upper Respiratory Specimens of Infected Patients. N Engl J Med, 2020.

22. World Health Organization. Coronavirus Disease (COVID-19). Situation Report - 162. 2020.

23. World Health Organization. COVID-19 response, 2020. 
24. World Health Organization. Practical actions in cities to strengthen preparedness for the COVID-19 pandemic and beyond, 2020.

25. Madhav N, Oppenheim B, Gallivan M, Mulembakani P, Rubin E, Wolfe N. Pandemics: Risks, Impacts, and Mitigation. In: Disease Control Priorities, 3th Edition. Improving Health and Reducing Poverty. The World Bank; 2017. p. 315-45.

26. World Health Organization. Strategic preparedness and response plan. 2020.

27. Saxena SK, Kumar S, Maurya VK, Sharma R, Dandu HR, Bhatt MLB. Current Insight into the Novel Coronavirus Disease 2019 (COVID-19). In: Saxena SK, Elsevier; 2020. p. 1-8.

28. World Health Organization. Operational planning guidelines to support country preparedness and response, 2020

29. Chien P. The consequences of the COVID-19 pandemic. BJOG: An International Journal of Obstetrics and Gynaecology. Blackwell Publishing Ltd; 2020. p. 917-8.

30. Checcucci E, Piramide F, Pecoraro A, Amparore D, Campi R, Fiori C, Elhage O, Kotecha P, Vyakarnam A, Serni S, Dasgupta P, Porpiglia F. The vaccine journey for COVID-19: a comprehensive systematic review of current clinical trials in humans. Panminerva Med, 2020.

31. Centers for Disease Control and Prevention. Interim PrePandemic Planning Guidance: Community Strategy for Pandemic Influenza Mitigation in the United States, 2007.

32. World Health Organization. Coronavirus disease (COVID-2019) Advice for the public, 2020.

33. Centers for Disease Control and Prevention. How to Protect Yourself \& Others, 2020.

34. Yin S, Peng Y, Ren Y, Hu M, Tang L, Xiang Z, Li X, Wang $\mathrm{M}$, Wang $\mathrm{W}$. The implications of preliminary screening and diagnosis: Clinical characteristics of 33 mild patients with SARS-CoV-2 infection in Hunan, China. J Clin Virol, 2020.

35. Pan American Health Organizartion. Understanding the infodemic and misinformation in the fight against COVID-19 department of evidence and intelligence for action in health, 2020.

36. World Health Organization. Countering misinformation about COVID-19, 2020.

37. European Comission. Social committee and the committee of the regions Tackling COVID-19 disinformation-Getting the facts right, 2020.

38. Ministério da Saúde. Fake News, 2020.

39. World Health Organization. Laboratory testing for coronavirus disease 2019 (COVID-19) in suspected human cases, 2020.

40. Hong KH, Lee SW, Kim TS, Huh HJ, Lee J, Kim SY, Park J-S, Kim GJ, Sung H, Roh KH, Kim J-S, Kim HS, Lee S-T, Seong M-W, Ryoo N, Lee H, Kwon KC, Yoo CK. Guidelines for Laboratory Diagnosis of Coronavirus Disease 2019 (COVID-19) in Korea. Ann Lab Med, 2020.

41. Ministério da Saúde. Guia de Vigilância Epidemiológica: Emergência de Saúde Pública de Importância Nacional pela Doença pelo Coronavírus 2019, 2020.

42. Chu DKW, Pan Y, Cheng SMS, Hui KPY, Krishnan P, Liu Y, Ng DYM, Wan CKC, Yang P, Wang Q, Peiris M, Poon LLM. Molecular Diagnosis of a Novel Coronavirus (2019-nCoV) Causing an Outbreak of Pneumonia. Clin Chem, 2020.
43. Corman VM, Landt O, Kaiser M, Molenkamp R, Meijer A, et al. Detection of 2019 novel coronavirus (2019-nCoV) by real-time RT-PCR. Eurosurveillance, 2020.

44. World Health Organization. Protocol: Real-time RT-PCR assays for the detection of SARS-CoV-2, 2020

45. Centers for Disease Control and Prevention. Real-Time RTPCR Diagnostic Panel For Emergency Use Only, 2020.

46. Green K, Winter A, Dickinson R, Graziadio S, Wolff R, Mallett S, Allen AJ. What tests could potentially be used for the screening, diagnosis and monitoring of COVID-19 and what are their advantages and disadvantages? Cent Evidence-Based Med Dev Promot disseminates better Evid Healthc, 2020.

47. Vogels CBF, Brito AF, Wyllie AL, Fauver JR, Ott IM, Kalinich CC, Petrone ME, Casanovas-Massana A, Muenker MC, Moore AJ, Klein J, Lu P, Lu-Culligan A, Jiang X, Kim DJ, Kudo E, Mao T, Moriyama M, Oh JE, Park A, Silva J, Song E, Takehashi T, Taura M, Tokuyama M, Venkataraman A, Weizman O-E, Wong P, Yang Y, Cheemarla NR, White E, Lapidus S, Earnest R, Geng B, Vijayakumar P, Odio C, Fournier J, Bermejo S, Farhadian S, Cruz C Dela, Iwasaki A, Ko AI, Landry M-L, Foxman EF, Grubaugh ND. Analytical sensitivity and efficiency comparisons of SARS-CoV-2 qRTPCR primer-probe sets. medRxiv, 2020.

48. World Health Organization. Coronavirus Disease (COVID-19) Technical Guidance: Laboratory Testing for 2019-nCoV in Humans, 2020.

49. Wang M, Wu Q, Xu W, Qiao B, Wang J, et al. Clinical diagnosis of 8274 samples with 2019-novel coronavirus in Wuhan Department of Clinical Laboratory, Renmin Hospital of Wuhan University, Wuhan Key Laboratory of Combinatorial Biosynthesis and Drug Discovery, Ministry of Education and School of P. medRxiv, 2020.

50. Yan Y, Chang L, Wang L. Laboratory testing of SARS-CoV, MERS-CoV, and SARS-CoV-2 (2019-nCoV): Current status, challenges, and countermeasures. Rev Med Virol, 2020.

51. Ye G, Li Y, Lu M, Chen S, Luo Y, Wang S, Wang Y, Wang $\mathrm{X}$. Experience of different upper respiratory tract sampling strategies for detection of COVID-19. J Hosp Infect, 2020.

52. Zhang W, Du R-H, Li B, Zheng X-S, Yang X-L, Hu B, Wang Y-Y, Xiao G-F, Yan B, Shi Z-L, Zhou P. Molecular and serological investigation of $2019-\mathrm{nCoV}$ infected patients: implication of multiple shedding routes. Emerg Microbes Infect, 2020.

53. WHO. Laboratory Guidelines for the Detection and Diagnosis of COVID-19 Virus Infection. Paho. 2020.

54. Wang $\mathrm{D}, \mathrm{Hu} \mathrm{B}, \mathrm{Hu} \mathrm{C}, \mathrm{Zhu} \mathrm{F}$, Liu $\mathrm{X}$, et al. Clinical Characteristics of 138 Hospitalized Patients with 2019 Novel Coronavirus-Infected Pneumonia in Wuhan, China. JAMA, 2020.

55. Liu W-D, Chang S-Y, Wang J-T, Tsai M-J, Hung C-C, Hsu C-L, Chang S-C. Prolonged virus shedding even after seroconversion in a patient with COVID-19. J Infect, 2020.

56. Chan JF-W, Yip CC-Y, To KK-W, Tang TH-C, Wong SC-Y, et al. Improved Molecular Diagnosis of COVID-19 by the Novel, Highly Sensitive and Specific COVID-19-RdRp/Hel Real-Time Reverse Transcription-PCR Assay Validated In Vitro and with Clinical Specimens. McAdam AJ, editor. J Clin Microbiol, 2020. 